Jurnal Pengabdian kepada Masyarakat

\title{
Penerapan Alat Praktek Air Conditioning (AC Trainer) pada SMK Negeri 5 Balikpapan
}

\author{
Syaeful Akbar ${ }^{1}$, Wahyu Anhar ${ }^{2 *}$, Basri $^{3}$ \\ 1,2,3 Politeknik Negeri Balikpapan, Jalan Soekarno Hatta, KM. 8 Balikpapan \\ *wahyu.anhar@poltekba.ac.id
}

\section{Kata Kunci: alat praktek, air conditioning}

Keywords: practice tool, air conditioning

\begin{abstract}
Abstrak Sistem air conditioning (AC) mempengaruhi kinerja, kenyamanan, dan kesehatan operator/penumpang kendaraan. Meningkatnya penggunaan perangkat AC pada kendaraan menyebabkan kebutuhan tenaga kerja ahli AC juga meningkat. Tidak adanya peralatan praktek AC pada sekolah kejuruan bidang keteknikan menyebabkan pelaksanaan pembelajaran menjadi tidak maksimal. Melalui kegiatan Pengabdian Kepada Masyarakat (PKM) Politeknik Negeri Balikpapan (Poltekba) tahun 2020 akan dibuat alat praktek AC, yang selanjutnya akan diterapkan kepada mitra pengabdian. Kegiatan pembuatan dan perakitan alat praktek AC terbagi dalam tiga bagian, yakni pembuatan dan perakitan bagian rangka, perakitan komponen AC, serta instalasi listrik. Penerapan alat praktek AC akan meningkatkan fasilitas pembelajaran mitra pengabdian khususnya dalam kegiatan praktek AC.
\end{abstract}

\begin{abstract}
The air conditioning (AC) system affects the performance, comfort and health of the vehicle operator/passenger. The increasing use of AC equipment in vehicles causes the need for skilled AC workers also increase. The absence of AC practice equipment in technical vocational schools causes the implementation of learning to be not optimal. Through the Community Service (PKM) activity of Politeknik Negeri Balikpapan (Poltekba) in 2020 an AC practice tool will be made, which will then be applied to service partners. The activity of manufacturing and assembling AC practical equipment is divided into three parts, manufacture and assembly of the frame, assembly of AC components, and electrical installations. The application of AC practice tools will improve the service partners learning facilities, especially in AC practice activities
\end{abstract}

\section{PENDAHULUAN}

Sistem Air Conditioning (AC) pada alat berat dan kendaraan ringan (light vehicle) menentukan kinerja dan kenyamanan bagi operator/penumpang. Selain itu kinerja AC yang baik juga akan berpengaruh terhadap kesehatan operator. Saat ini perangkat AC merupakan hal mutlak yang harus ada pada kendaraan (Krishnaswamy, dkk., 2020). Penggunaan AC pada kendaraan sangat tinggi dan terus meningkat tiap tahunnya (Huang, dkk., 2006). Berdasarkan pemakaian kendaraan rata-rata 249 jam tiap tahunnya, maka penggunaan AC saat berkendara mengambil durasi 107 hingga 121 jam atau 43 hingga 49\% dari penggunaan kendaraan (Sukri, dkk., 2016). Selain itu, kinerja AC sangat berpengaruh terhadap efisiensi energi kendaraan (Kristanto \& Leephakpreeda, 2017; 
Yang, dkk., 2019). Tingginya penggunaan dan jaminan kualitas kinerja AC pada kendaraan menyebabkan kebutuhan tenaga kerja ahli dalam bidang perawatan dan perbaikan AC juga ikut meningkat.

Beberapa Sekolah Menengah Kejuruan (SMK) bidang keteknikan di Kota Balikpapan menyelenggarakan Jurusan Otomotif dan Alat Berat. Salah satu kompetensi yang diajarkan kepada siswa adalah kompetensi AC. Berdasarkan kegiatan observasi PKM Poltekba tahun 2020 bahwa beberapa sekolah kejuruan yang menyelenggarakan pembelajaran tentang AC belum memiliki alat praktek AC. Kegiatan praktek merupakan aktivitas pembelajaran yang harus dilakukan untuk memenuhi standar kompetensi siswa (Faludi \& Gilbert, 2019), khususnya berkaitan dengan kompetensi AC. Salah satu sekolah kejuruan yang belum memiliki alat praktek AC adalah SMK Negeri 5 Balikpapan.

Oleh karena itu, tim PKM Poltekba tahun 2020 menjalin kerjasama dengan SMK Negeri 5 Balikpapan sebagai mitra kerjasama dalam kegiatan pengabdian. Berdasarkan permasalahan yang terjadi pada mitra, maka kegiatan PKM menitikberatkan peningkatan fasilitas pembelajaran praktek melalui pembuatan dan penerapan alat praktek AC.

\section{METODOLOGI}

Alur pelaksanaan kegiatan PKM seperti ditunjukkan dalam Gambar 1. Kegiatan PKM dimulai dengan observasi oleh tim PKM Poltekba. Kegiatan observasi bertujuan untuk mengetahui kondisi dan situasi sebenarnya dari mitra pengabdian. Berdasarkan kegiatan observasi, penentuan solusi penyelesaian masalah akan menjadi lebih tepat dan akurat. Kesepakan kerjasama pengabdian dengan mitra juga dilaksanakan sebelum kegiatan PKM.

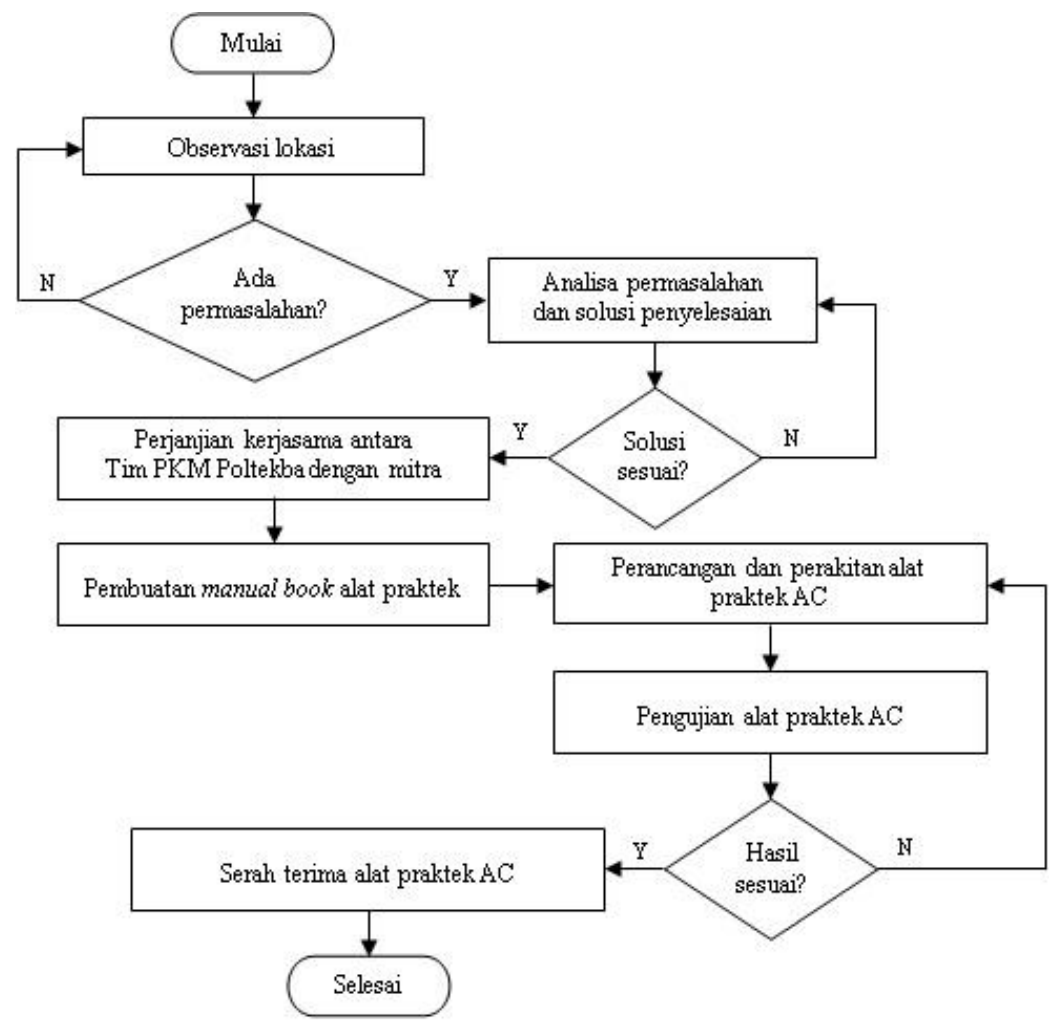

Gambar 1. Alur pelaksanaan PKM 
Kegiatan utama dalam PKM Poltekba adalah pembuatan dan perakitan alat praktek AC. Kegiatan pembuatan dan perakitan alat praktek AC dilaksanakan di Workshop Jurusan Teknik Mesin Poltekba. Kegiatan PKM Poltekba dalam pembuatan dan perakitan melibatkan mahasiswa Poltekba. Pengujian alat dilakukan setelah alat selesai dibuat dan dirakit. Pengujian alat bertujuan untuk memastikan kinerja dan kondisi alat sebelum diserahkan kepada mitra pengabdian. Selain itu, untuk memudahkan bagi mitra dalam mengoperasikan alat maka tim PKM Poltekba membuat panduan teknis penggunaan alat.

\section{HASIL DAN PEMBAHASAN}

Kegiatan pembuatan dan perakitan alat terdiri dari tiga bagian, yakni pembuatan dan perakitan bagian rangka, perakitan komponen $\mathrm{AC}$, serta instalasi listrik.
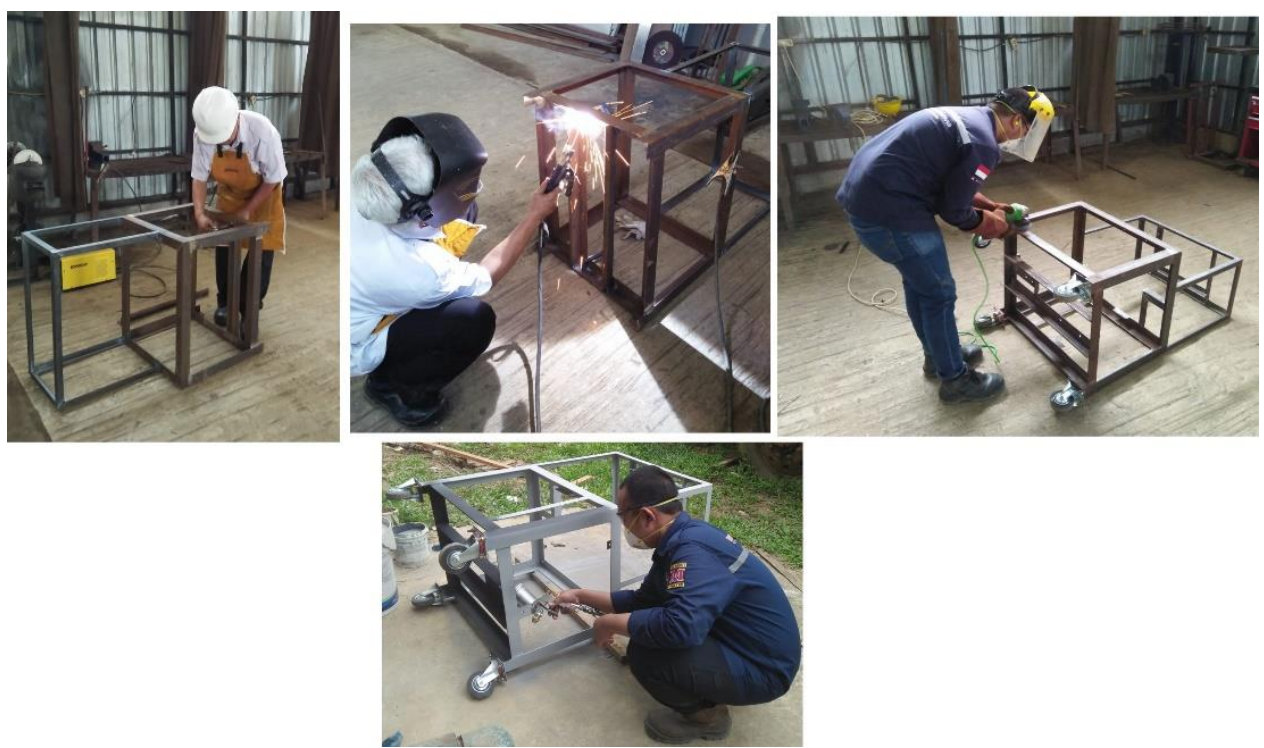

Gambar 2. Pembuatan dan perakitan rangka alat

Gambar 2 menunjukkan beberapa proses pembuatan dan perakitan rangka alat praktek AC. Setelah rangka alat selesai maka dilanjutkan dengan perakitan komponen AC pada rangka alat.

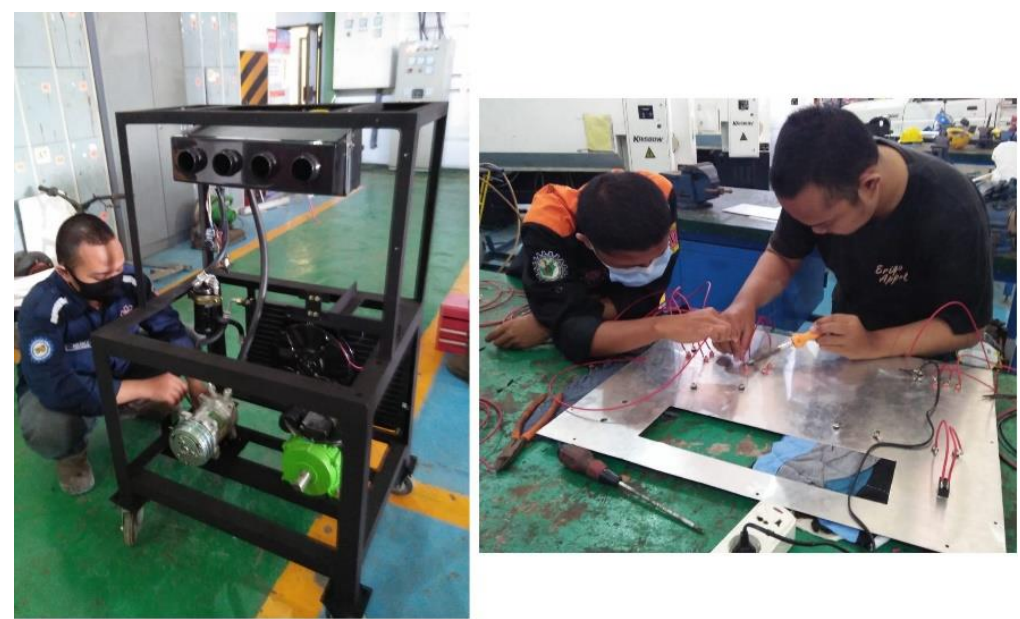

Gambar 3. Perakitan komponen AC dan instalasi listrik 
Gambar 3 menunjukkan beberapa proses perakitan komponen AC pada rangka dan juga instalasi kelistrikan alat. Komponen utama AC yang digunakan adalah evaporator, compressor, condenser, dan expansion valve (Li, dkk., 2017). Selain itu, jika melihat dalam Gambar 4 bahwa instalasi listrik alat menggunakan banana jack yang saling dihubungkan pada masing-masing komponen listrik (sesuai dengan simbol komponen listrik). Tujuan pembuatan seperti ini adalah agar siswa juga menguasai instalasi kelistrikan dalam sistem AC. Jika keliru dalam menghubungkan instalasi listriknya maka alat praktek AC tidak bisa aktif $(O F F)$.

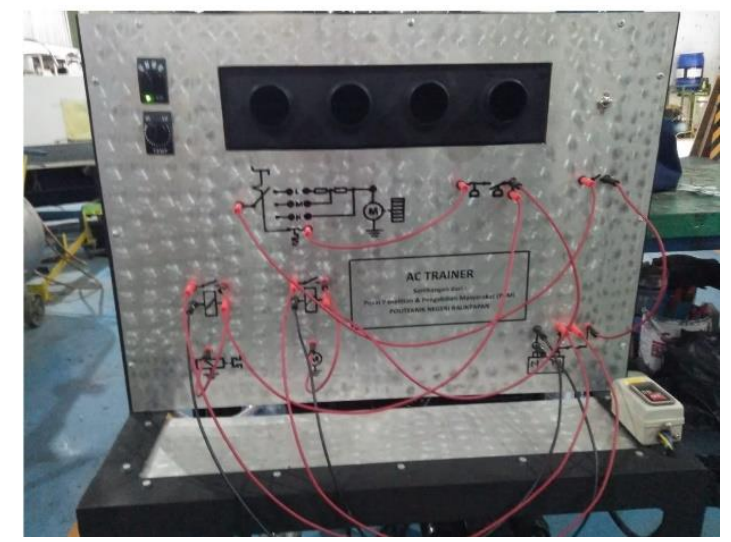

Gambar 4. Rangkaian instalasi listrik alat praktek AC

Alat yang telah selesai dirakit, selanjutnya dilakukan pengujian. Pengujian alat dilakukan untuk memastikan kondisi dan kinerja alat. Selain itu, untuk memastikan tidak terjadi kebocoran pada sistem instalasi AC. Sistem AC menggunakan gas refrigerant dalam pengoperasiannya. Kebocoran pada sistem AC akan menyebabkan keluarnya gas refrigerant yang dapat berdampak terhadap lingkungan yakni pemanasan global (Bellos \& Tzivanidis, 2019; Ma, dkk., 2020; Park, dkk., 2019). Alat praktek AC yang telah selesai dan siap untuk digunakan oleh mitra pengabdian seperti ditunjukkan dalam Gambar 5.
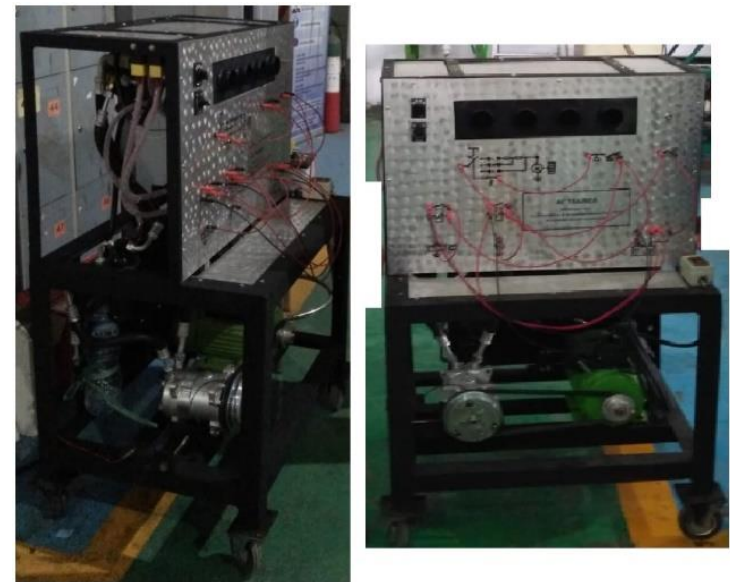

Gambar 5. Alat praktek AC 
Akhir dari kegiatan PKM Poltekba adalah penyerahan alat praktek AC kepada mitra pengabdian. Gambar 6 menunjukkan kegiatan penyerahan alat praktek AC kepada mitra pengabdian.
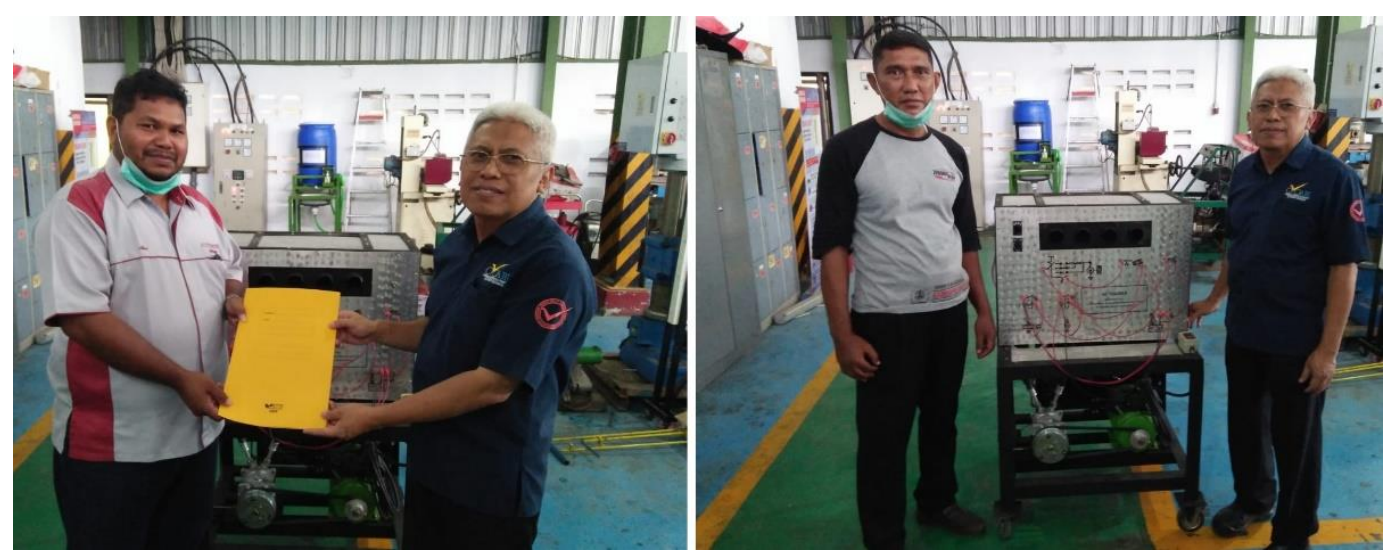

Gambar 6. Penyerahan alat praktek AC

\section{KESIMPULAN}

Kegiatan PKM Poltekba tahun 2020 adalah penerapan alat praktek AC pada SMK Negeri 5 Balikpapan. Kegiatan PKM Poltekba bertujuan untuk meningkatkan fasilitas pembelajaran praktek AC. Tim PKM Poltekba telah dapat membuat dan merakit alat praktek AC, serta menyerahkan alat praktek AC tersebut kepada SMK Negeri 5 Balikpapan.

\section{Ucapan Terima Kasih}

Kegiatan PKM Poltekba tahun 2020 dapat terlaksana berkat pendanaan yang bersumber dari DIPA internal Kegiatan PKM Poltekba 2020 ini juga dapat terlaksana berkat sarana dan prasarana Workshop Jurusan Teknik Mesin Poltekba. Selain itu, tim PKM Poltekba mengucapkan terima kasih atas kerjasama dan kepercayaan SMK Negeri 5 Balikpapan dalam memberikan kesempatan kepada tim PKM Poltekba untuk menyelesaikan permasalahan dalam kegiatan pembelajaran.

\section{Daftar Pustaka}

Bellos, E., \& Tzivanidis, C. (2019). Investigation of the Environmentally-Friendly Refrigerant R152a for Air Conditioning Purposes. Applied Sciences, 119 (9), 121. doi:10.3390/app9010119

Faludi, J., \& Gilbert, C. (2019). Best practices for teaching green invention: Interviews on design, engineering, and business education. Journal of Cleaner Production, 234, 1246-1261. doi:https://doi.org/10.1016/j.jclepro.2019.06.246

Huang, K. D., Tzeng, S. C., Jeng, T. M., \& Chiang, W. D. (2006). Air-conditioning system of an intelligent. Applied Energy, 83, 545-557. doi:10.1016/j.apenergy.2005.05.006

Krishnaswamy, H., Muthukrishnan, S., Thanikodi, S., Arockiaraj, G. A., \& Venkatraman, V. (2020). Investigation of air conditioning temperature variation by modifying 
the structure of passenger car using computational fluid dynamics. Thermal Science, 24, 495-498.

Kristanto, D., \& Leephakpreeda, T. (2017). Sensitivity Analysis of Energy Conversion for Effective Energy Consumption, Thermal Comfort, and Air Quality within Car Cabin. Energy Procedia, 138, 552-557. doi:10.1016/j.egypro.2017.10.158

Li, K. Y., Luo, W. J., Huang, J. Z., Chan, Y. C., Pratikto, \& Faridah, D. (2017). Operational Temperature Effect on Positioning Accuracy of a Single-Axial Moving Carrier. Applied Science, 420 (7), 1-14. doi:10.3390/app7040420

Ma, Z., Liu, F., Tian, C., Jia, L., \& Wu, W. (2020). Experimental comparisons on a gas engine heat pump using R134a and low-GWP refrigerant R152a. International $\begin{array}{llll}\text { Journal of } & \text { Refrigeration, }\end{array}$ doi:https://doi.org/10.1016/j.ijrefrig.2020.03.007

Park, J., Jung, I., Choi, W., Choi, S. O., \& Han, S. W. (2019). Greenhouse gas emission offsetting by refrigerant recovery from WEEE: A case study on a WEEE recycling plant in Korea. Resources, Conservation \& Recycling, 142, 167-176. doi:https://doi.org/10.1016/j.resconrec.2018.12.003

Sukri, M. F., Musa, M. N., Senawi, M. Y., \& Nasution, H. (2016). Modeling and Parametric Study of Cooling Loads Characteristics for Automotive AirConditioning System. Applied Mechanics and Materials, 819, 189-201. doi:10.4028/www.scientific.net/AMM.819189

Yang, C. J., Yang, T. C., Chen, P. T., \& Huang, K. D. (2019). An Innovative Design of Regional Air Conditioning to Increase Automobile Cabin Energy Efficiency. Energies, 2352 (12), 1-16. doi:10.3390/en12122352 